\title{
The elastic recovery, ejection work, strength and dissolution of instant coffee tablet containing croscarmellose sodium disintegrant
}

\author{
${ }^{1}$ Mohd Rosidi, N.S., ${ }^{1, *}$ Anuar, M.S. and ${ }^{2}$ Tahir, S.M. \\ ${ }^{1}$ Department of Process and Food Engineering, Faculty of Engineering, Universiti Putra Malaysia, 43400 \\ UPM Serdang, Selangor, Malaysia. \\ ${ }^{2}$ Department of Mechanical and Manufacturing Engineering, Faculty of Engineering, Universiti Putra \\ Malaysia, 43400 UPM Serdang, Selangor, Malaysia.
}

\section{Article history: \\ Received: 10 April 2020 \\ Received in revised form: 26 \\ May 2020 \\ Accepted: 11 July 2020 \\ Available Online: 3 January \\ 2021}

\section{Keywords:}

Instant coffee tablet,

Compaction,

Elastic recovery,

Ejection,

Dissolution,

Tablet strength

DOI:

https://doi.org/10.26656/fr.2017.5(S1).003

\begin{abstract}
Croscarmellose sodium disintegrant agent, commonly used in the pharmaceutical tablet formulation was employed in the instant coffee tablet formulation. Various compositions of croscarmellose sodium were added to the instant coffee tablet formulation; $20 \% \mathrm{w} / \mathrm{w}$, $40 \% \mathrm{w} / \mathrm{w}, 60 \% \mathrm{w} / \mathrm{w}$ and $80 \% \mathrm{w} / \mathrm{w}$ respectively. These mixtures were then compacted through the uniaxial die compaction process forming $1 \mathrm{~g}$ tablets having $13 \mathrm{~mm}$ diameters each at various compaction pressures of $37.7 \mathrm{MPa}, 75.4 \mathrm{MPa}, 113.0 \mathrm{MPa}$ and $150.7 \mathrm{MPa}$. The ejection work done when ejecting the tablet from the die was calculated to represent the frictional resistance to tablet motion during ejection. The tablet elastic recovery was measured as a quantitative measure of the tablet physical dimensional stability. Meanwhile, the mechanical strength, as well as the tablet dissolution, were also measured. The results showed that the croscarmellose composition and the compaction pressure affected all the studied tabletting properties. Generally, croscarmellose sodium increased the tablet elastic recovery and lowered the tablet ejection work, tensile strength and dissolution time in experimental conditions employed in this work. However, the extent of the croscarmellose sodium influence was clearly dependent upon the compaction pressures used for instant coffee tablet formation.
\end{abstract}

\section{Introduction}

Coffee is one of the major industrial crops in Malaysia. In 2018, there was approximately 1930.1 ha of planted area in Malaysia for coffee crop-producing 3369.2 Mt of coffee (Department of Agriculture Malaysia, 2018). In Malaysia, the market for instant coffee is dominated by small and medium enterprises (SMEs), where the overcrowding of the market occurs thus the marketing strategy is important in ensuring the instant coffee product will be favourable amongst the consumers (Sheriff et al., 2016). Therefore, new innovations must be made in order to attract consumers such as the use of coffee in the form of tablets (Eurotab, 2016). Compacting food powder material into tablet form is a simple processing method to reduce the volume of the powder material into a smaller and more precise form for human consumption. A number of researches have been conducted to examine the viability of different food powder products to be compacted into tablet forms (Shamsudin et al., 2012; Shamjuddin et al., 2014). These previous works show that the formulation plays a key role in determining the two important physical criteria for food tablet that is its strength in maintaining its form during handling until consumer consumption and its ability to disintegrate when it comes into contact with the intended liquid phase. Notwithstanding, there are also other important criteria such as the tablet stability in terms of its physical dimensions (Hwang et al., 2001; Picker, 2001) and ultimately, the customer acceptance of the tableted food product as an acceptable replacement to the traditional form of the food.

This work explores the possibility of adding a disintegration agent to coffee powders and subsequently compacting this mixture into tablet form. A disintegration agent works by facilitating the disintegration of the tablet upon contact with an aqueous phase. There are several mechanisms of how a disintegration agent acts. One way is that it can facilitate the water uptake into the tablet pores that will cause the tablet to be reduced into smaller fragments (Desai et al., 2016; Markl and Zeitler, 2017). Another route is through 
the swelling mechanism whereby the tablet will be ruptured due to the swelling of the disintegrant particles within the tablet structure upon adsorption of the water molecules (Desai et al., 2016; Markl and Zeitler, 2017). Recently, the use of an effervescent agent in coffee tablet formulations was studied (Jamar et al., 2019). They have found that significant reduction in the coffee tablet disintegration time was obtained with the addition of an effervescent agent. The effervescent agent can also be regarded as a disintegrant agent, although it helps to break the tablet bonding through the liberation of carbon dioxide gases when it comes into contact with water (Ipci et al., 2016).

In this current work, croscarmellose sodium will be added into the instant coffee tablet as a disintegrant aid. Croscarmellose sodium is one of the synthetic disintegrants commonly utilized by the pharmaceutical industry in tablet formulation. The tablet dimensional changes, frictional effects during processing, tablet mechanical strength and dissolution will be conducted in order to assess the technical performance of the instant coffee tablet containing this chosen disintegrant.

\section{Material and methods}

\subsection{Materials and sample preparation}

The instant coffee (3 in 1 Charcoal Roasted Ipoh White Coffee, Super Food Ltd, Singapore) was procured from the local supermarket. Meanwhile, the croscarmellose sodium (Acdisol) used as the disintegrant was obtained from FMC Biopolymer, USA. In this experiment, the instant coffee and the croscarmellose sodium were mixed at various mass compositions of $80 \% \mathrm{w} / \mathrm{w}$ instant coffee $+20 \% \mathrm{w} / \mathrm{w}$ croscarmellose sodium, $60 \%$ w/w instant coffee $+40 \%$ w/w croscarmellose sodium, $40 \% \mathrm{w} / \mathrm{w}$ instant coffee $+60 \%$ $\mathrm{w} / \mathrm{w}$ croscarmellose sodium and $20 \% \mathrm{w} / \mathrm{w}$ instant coffee $+80 \% \mathrm{w} / \mathrm{w}$ croscarmellose sodium using a dry powder rotator (Glas-Col, USA).

\subsection{Tablet formation: compaction process}

About $1 \mathrm{~g}$ of the powder mixture prepared previously was then inserted into a $13 \mathrm{~mm}$ stainless steel die set (Specac, UK) and compacted using a universal testing machine (model 3382, Instron, USA) therefore producing $13 \mathrm{~mm}$ tablets weighing $1 \mathrm{~g}$ each. Various compaction pressure values were used for compacting the powder sample inside the die, which were $37.7 \mathrm{MPa}$, 75.4 $\mathrm{MPa}, 113.0 \mathrm{MPa}$ and $150.7 \mathrm{MPa}$ respectively. The speed that was used during the loading stage of the compaction process was $0.1 \mathrm{~mm} / \mathrm{s}$ and during the unloading stage was $0.167 \mathrm{~mm} / \mathrm{s}$.

\subsection{Tablet frictional resistance during ejection}

After the tablet was formed within the die set, the tablet was then ejected from the die set using the same universal testing machine used during the tablet formation. The ejection force-displacement was recorded and the area under this force-displacement curve was taken as the ejection work done when pushing the tablet out from the die cavity. This was then used as a quantitative measure of the tablet frictional resistance during the ejection stage of the compaction process.

\subsection{Tablet elastic recovery}

The tablet elastic recovery (ER) that described that the percentage of axial expansion of a tablet was calculated using Equation 1 (Shamjuddin et al., 2014):

$$
\operatorname{ER}(\%)=\frac{H_{x}-H_{c}}{H_{c}} \times 100
$$

Where $H_{c}=$ tablet height at the compaction pressure used for tablet formation (m) and $H_{x}=$ height of the tablet after $24 \mathrm{hrs}(\mathrm{m})$

\subsection{Tablet mechanical strength}

The tablet mechanical strength was determined using the established Brazilian diametrical tensile strength test (Fell and Newton, 1970). The load needed to fracture diametrically the tablet was then used to calculate the tablet tensile strength using Equation 2:

$$
\sigma=\frac{2 F}{\Pi d t}
$$

Where $\sigma=$ tensile strength of the tablet $\left(\mathrm{Nm}^{-2}\right) ; F=$ load needed to cause fracture $(\mathrm{N}) ; d=$ tablet diameter $(\mathrm{m})$; and $t=$ tablet thickness (m)

\subsection{Tablet dissolution}

In this experiment, one tablet sample was placed inside a beaker containing $22 \mathrm{~mL}$ of water that was maintained at a constant temperature of $80^{\circ} \mathrm{C}$. The stirrer speed was set at $300 \mathrm{rpm}$. The dissolution time of the tablet was taken as the time when the tablet had fully dissolved. This was conducted through manual physical observation of the tablet dissolution process in the beaker by the personnel involved in the experiment.

\section{Results and discussion}

The elastic recovery of the instant coffee tablets generally increased when higher amounts of the croscarmellose sodium disintegrant were present in the tablet formulation as illustrated in Figure 1. Previous studies also showed that the addition of a disintegrant in a tablet formulation increased the elastic recovery of the tablet (Shamjuddin et al., 2014). The compaction 


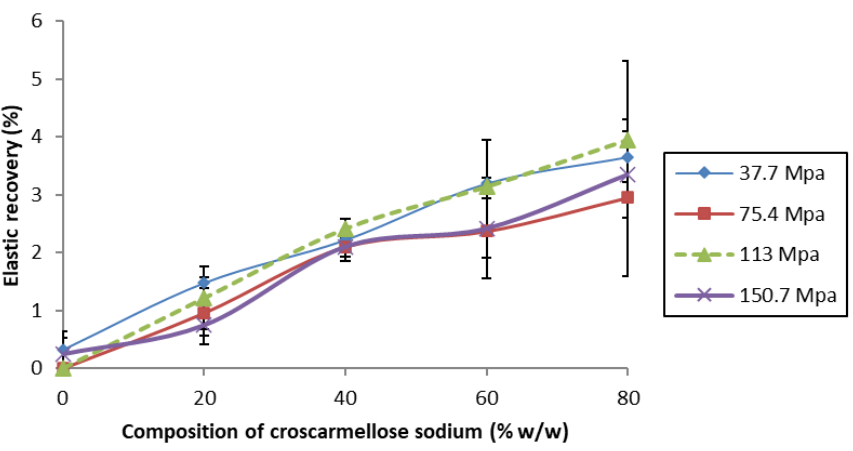

Figure 1. Elastic recovery of instant coffee tablets at various croscarmellose sodium compositions and compaction pressures.

pressures did not show clear effects on the elastic recovery of the instant coffee tablets in comparison to the croscarmellose sodium compositions. The elastic recovery in this work measured the height expansion of the tablets. Hence, the increased in the tablet height expansion experienced could be caused by the released of the tablet stored elastic energies (Shamjuddin et al., 2014). Other possible causes could also be due to the moisture adsorption of the tablets from the surroundings leading to the swelling of the tablet structure promoting the tablet to increase in its height. The extent of these two possible mechanisms that promote the tablet height expansion after the compaction process would need to be further studied in order to distinguish the extent of these two mechanisms on the observed instant coffee tablet elastic recovery. A relatively high degree of elastic recovery experienced by a tablet could cause tablet defects such as cracks and undermined the tablet mechanical integrity.

The addition of $20 \% \mathrm{w} / \mathrm{w}$ croscarmellose sodium to the instant coffee tablet generally lowered the work done in ejecting the tablet from the die cavity in comparison with the pure instant coffee tablets that did not contain any disintegrant (Figure 2). Further addition of croscarmellose sodium resulted in a relatively constant ejection work except for the case at the highest compaction pressure of $150.7 \mathrm{MPa}$, where fluctuations in the measured ejection works were obtained. The tablet stored elastic energies caused the tablet to expand diametrically onto the die walls during ejecting (Anuar and Briscoe, 2009, 2010). This would then gave rise to the resistance to tablet motion due to frictional effects between the tablet and the die wall surfaces.

The instant coffee tablet tensile strength values were observed to drop with the addition of $20 \%$ w/w croscarmellose sodium disintegrant for all the compaction pressures used except at the highest compaction pressure of $150.7 \mathrm{MPa}$ that showed instead an increase in the tablet tensile strength values as shown in Figure 3. This was in contrast with the results obtained

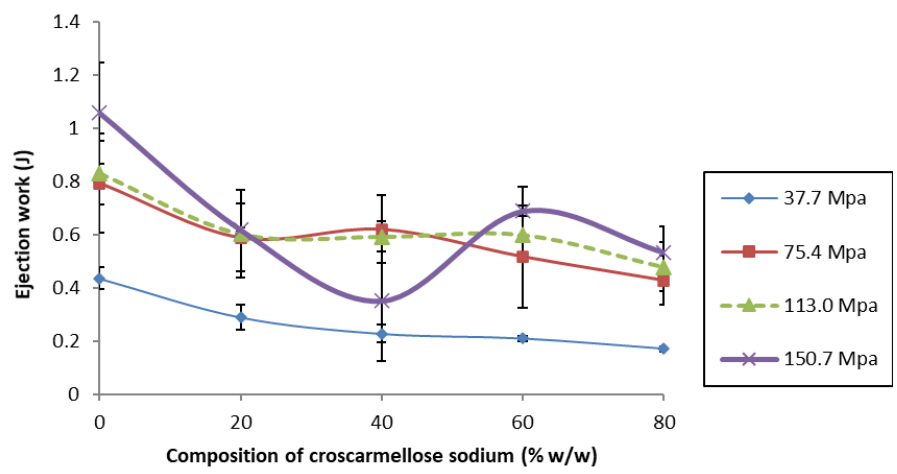

Figure 2. Ejection work values for the instant coffee tablets at various croscarmellose sodium compositions and compaction pressures.

when adding croscarmellose sodium to lactose tablets, where generally the increase in the tablet strength values was found (Yaakub et al., 2018). The increased in the croscarmellose sodium composition was seen to lower further the instant coffee tablet tensile strength reaching asymptotically constant tensile strength values at high compositions of $60 \% \mathrm{w} / \mathrm{w}$ and $80 \% \mathrm{w} / \mathrm{w}$. It was also evident from Figure 3 that the influence of the croscarmellose composition on the instant coffee tablet tensile strength values were the lowest at the highest compaction pressure used in this work at $150.7 \mathrm{MPa}$. Higher compaction pressures used to form the tablets also resulted in producing a mechanically stronger tablet, where the higher plastic deformation of the particles incurred at higher compaction pressures resulting in higher contact area available for bond formation.

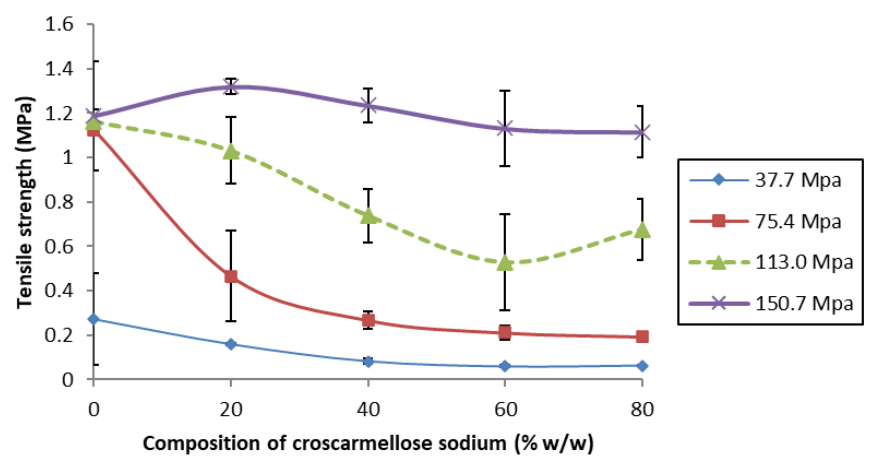

Figure 3. Instant coffee tablet tensile strength at various croscarmellose sodium compositions and compaction pressures.

All the tablets formed at the various compaction pressures used in this work exhibited decreased dissolution times upon the addition of the croscarmellose sodium disintegrant (Figure 4). However, the extent of croscarmellose sodium additions in shortening the dissolution times was clearly dependent upon the compaction pressures used for tablet formation. For the case at the highest compaction pressure of $150.7 \mathrm{MPa}$, the dissolution time was not affected by the addition of $20 \% \mathrm{w} / \mathrm{w}$ croscarmellose sodium. Faster dissolution was only observed after the further increase to $40 \% \mathrm{w} / \mathrm{w}$ croscarmellose sodium. Generally, the dissolution time 
approached a constant value upon further addition of croscarmellose sodium up until $60 \% \mathrm{w} / \mathrm{w}$ croscarmellose sodium composition, where above this, a slight increase in the dissolution time was observed. The weaker interparticulate bonding for the instant coffee tablets containing croscarmellose sodium disintegrant compared to a pure instant coffee tablet (Figure 3) could be one of the major factors in further enhancing the dissolution of the tablet apart from the disintegrant swelling mechanism in disrupting the tablet inter-particulate bonding upon contact with water.

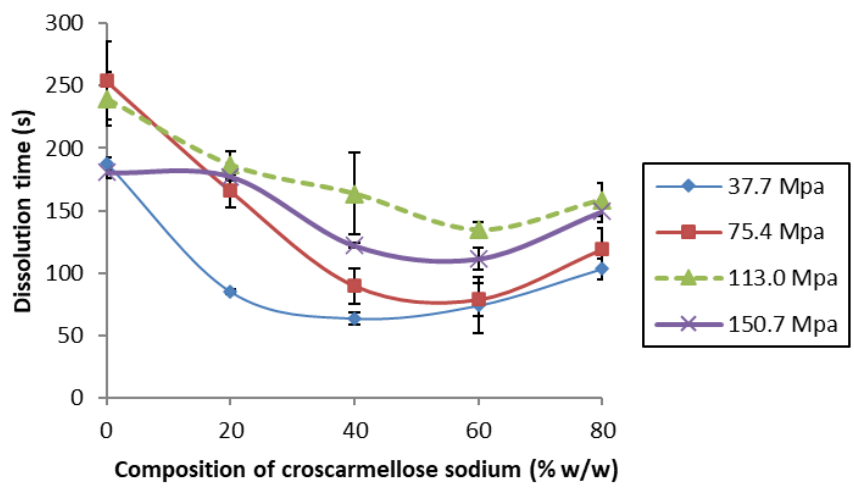

Figure 4. Dissolution time of instant coffee tablets at various croscarmellose sodium compositions and compaction pressures.

\section{Conclusion}

Instant coffee tablets containing various croscarmellose sodium compositions were formed in this work. The addition of croscarmellose sodium increased the tablet elastic recovery and lowered the tablet ejection work, tensile strength and dissolution time in the experimental range used. The extent of these general observations was clearly dependent upon the compaction pressure used for instant coffee tablet formation. Based on the results, it is recommended that the amount of croscarmellose sodium disintegrant should be below $60 \% \mathrm{w} / \mathrm{w}$ and the use of compaction pressures lower than $75.4 \mathrm{MPa}$ to promote fast instant coffee tablet dissolution but other factors such as customer sensorial acceptance should also be considered when formulating the instant coffee tablet.

\section{Acknowledgement}

The authors gratefully acknowledging the financial support given by Universiti Putra Malaysia in conducting this research work. The authors gratefully acknowledging the financial support obtained from UPM IPS grant Vot no: 9660700 .

\section{References}

Anuar, M.S. and Briscoe, B.J. (2009). The elastic relaxation of starch tablets during ejection. Powder
Technology, 195(2), 96-104. https://doi.org/10.1016/ j.powtec.2009.05.019

Anuar, M.S. and Briscoe, B.J. (2010). Interfacial elastic relaxation during the ejection of bi-layered tablets. International Journal of Pharmaceutics, 387(1-2), 42-47. https://doi.org/10.1016/j.ijpharm.2009.11.031

Department of Agriculture Malaysia (DOA) (2018). Industrial crop statistics. Putrajaya: Department of Agriculture Malaysia.

Desai, P.M., Liew, C.V. and Heng, P.W.S. (2016). Review of disintegrants and the disintegration phenomena. Journal of Pharmaceutical Science, 105 (9), P2545-P2555. https://doi.org/10.1016/ j.xphs.2015.12.019

EUROTAB. (2016). Introducing the instant coffee tablet. Retrieved on November 11, 2019 from International Communicaffe website: https:// www.comunicaffe.com/introducing-the-instantcoffee-tablet/.

Fell, J.T. and Newton, J. M. (1970). Determination of tablet strength by diametral compression test. Journal of Pharmaceutical Sciences, 59(5), 688-691. https://doi.org/10.1002/jps.2600590523

Hwang, R., Peck, G.R., Besserman, D.M., Friedrich, C.E. and Gemoules, M.K. (2001). Tablet Relaxation and Physicomechanical stability of lactose, microcrystalline cellulose, and dibasic calcium phosphate. Pharmaceutical Technology, November 2001, 54-80.

Ipci, K., Oktemer, T., Birdane, L., Altintoprak, N., Muluk, N.B., Passali, D., Lopatin, A., Bellusi, L., Mladina, R., Pawankar, R. and Cingi, C. (2016). Effervescent tablets: a safe and practical delivery system for drug administration. ENT Updates, 6(1), 46-50. https://doi.org/10.2399/jmu.2016001009

Jamar, A., Anuar, M.S. and Tahir, S.M. (2019). Frictional effects, mechanical strength, and disintegration of coffee mix tablet, effervescent coffee mix tablet and with added lubricant. Particulate Science and Technology, 2019, 1666950. https://doi.org/10.1080/02726351.2019.1666950

Markl, D. and Zeitler, J.A. (2017). A review of disintegration mechanisms and measurement techniques. Pharmaceutical Research, 34, 890-917. https://doi.org/10.1007/s11095-017-2129-z

Picker, K.M. (2001). Time dependence of elastic recovery for characterization of tabletting materials. Pharmaceutical Development and Technology, 6(1), 61-70. https://doi.org/10.1081/PDT-100000014

Shamjuddin, A., Anuar, M.S. and Tahir, S.M. (2014). Characteristics of tableted Roselle (Hibiscus sabdariffa Linn.) with addition of sodium starch 
glycolate. Particulate Science and Technology: An International Journal, 32(4), 384-391. https:// doi.org/10.1080/02726351.2014.880095

Shamsudin, I.S., Anuar, M.S. and Tahir, S.M. (2012). Compaction of sweet potato (Ipomoea batatas L.) and stevia rebaudiana food powders. Particulate Science and Technology, 30(2), 135-144. https:// doi.org/10.1080/02726351.2011.552098

Sheriff, N.M., Ismail, H., Abu Bakar, Z.I. and Damain, D. (2016). Coffee marketing: what matters to coffee drinkers? Jurnal Intelek, 10(2), 15-28.

Yaakub, N.A., Anuar, M.S. and Tahir, S.M. (2018). Compaction behaviour and mechanical strength of lactose-sodium starch glycolate and lactosecroscarmellose sodium binary tablets. IOP Conference Series: Materials Science and Engineering, 342, $012026 . \quad \mathrm{https}: / /$ doi.org/10.1088/1757-899X/342/1/012026 